\title{
Efecto de las Variables de Proceso sobre la Cinética de Acidificación, la Viabilidad y la Sinéresis del Suero Costeño Colombiano
}

\section{Diofanor Acevedo ${ }^{1^{*}}$, Aida Rodríguez ${ }^{2}$ y Alejandro Fernández ${ }^{2}$}

(1) Universidad de Cartagena, Programa Ingeniería de Alimentos, Calle de la Universidad No 36-100, Cartagena-Colombia (e-mail: diofanor3000@gmail.com)

(2) Universidad del Valle, Facultad de Ingeniería, Escuela de Ingeniería de Alimentos,

Calle 13 No 100-00, Cali-Colombia (e-mail: aidrodri@univalle.edu.co, alfernan@univalle.edu.co)

*autor a quien debe ser dirigida la correspondencia

\begin{abstract}
Resumen
En el presente estudio se analizaron los efectos simultáneos de la temperatura de fermentación, el nivel de sólidos totales y la concentración del inóculo sobre la acidificación, la sinéresis y la viabilidad del Suero Costeño, un producto lácteo fermentado tradicional de Colombia. Para ello se usó la metodología de superficie de respuesta con tres variables y cinco niveles. La fermentación se realizó con las bacterias lácticas Lactococcus lactis Subs. Lactis (ATCC29146) y Lactobacillus Paracasei Subs paracasei (ATCC 334). El tratamiento estadístico dio lugar a la generación de modelos matemáticos, con los cuales se determino que los sólidos totales disminuyen la velocidad máxima de acidificación y la sinéresis del suero, mientras la temperatura afecta significativamente la viabilidad de las bacterias acido lácticas.
\end{abstract}

Palabras clave: suero costeño, cinética de acidificación, sinéresis, sólidos totales

\section{Effect of the Process Variables on the Kinetics of Acidity, Viability and Syneresis of the Colombian Coastal Whey}

\begin{abstract}
In the present study the simultaneous effect of fermentation temperature, milk total solid level and total inoculums concentration on the acidification process, syneresis and viability of Colombian coastal whey, a fermented milk product, traditional of Colombia. For this the response surface methodology with three variables and five levels was employed. Fermentation was done using the bacteria Lactococcus lactis Subs. Lactis (ATCC29146) and Lactobacillus Paracasei Subs paracasei (ATCC 334). The statistical analysis allowed generating mathematical models that were used to determine that the total solids significantly decreased the maximum rate of acidification and syneresis of costal whey, while the temperature significantly affects the viability of lactic acid bacteria.
\end{abstract}

Keywords: Colombian coastal whey, acidification kinetics, syneresis, total solids 


\section{INTRODUCCIÓN}

El "Suero Costeño" es un producto lácteo fermentado elaborado tradicionalmente en la Costa Atlántica Colombiana, producido por la acidificación espontánea de la leche cruda, debido a la acción de los microorganismos autóctonos. Se diferencia de las leches fermentadas porque hay ruptura del gel, desuerado y adición de sal $(\mathrm{NaCl})$. El producto final es similar a la crema agria y se emplea como aderezo. Su fermentación forma un sistema de dos fases: una liquida y otra sólida; donde la parte liquida es Ilamada lactosuero y la otra es conocida como "suero" (Chamie y García, 1999). La demanda creciente de los consumidores hacia productos más naturales que contengan menos o ningún aditivo o estabilizantes ha motivado la investigación del uso de componentes de la misma leche o el control de las variables de proceso para mejorar los productos lácteos.

La temperatura de fermentación espontánea del "Suero Costeño" es el factor que más influye en el crecimiento de los microorganismos, y por tanto en los valores de $\mathrm{pH}$, acidez y lactosa obtenidos en el producto. Las bacterias ácido lácticas (BAL) que han sido aisladas depende del sitio donde se produce y de la etapa del proceso (filtración, estandarización, tratamiento térmico, enfriamiento, inoculación, incubación, separación y ruptura del coagulo, salado y homogenización) dentro de estas están: Lactococcus lactis, Lactobacillus paracasei, Lactobacillus brevis y Enterococcus faecium. (Farelo, 2002).

La actividad acidificante de las bacterias acido lácticas durante la fermentación puede ser descrita a través de las curvas de $\mathrm{pH}$, midiendo la disminución del $\mathrm{pH}$ en intervalos de tiempo, la velocidad máxima de acidificación (Vmax) puede ser calculada como dpH/dt de acuerdo a (Kristo y Biladeris, 2003a) y es uno de los parámetros que mejor describe la cinética de acidificación.

La sinéresis es la expulsión o separación del lactosuero debido a la contracción del gel esto afecta la calidad de los productos lácteos, porque se observa líquido en la superficie causando el rechazo por el consumidor. Es debido al rearreglo de la red molecular de caseína después de la formación del gel. Los principales factores de procesos asociados con la sinéresis son: rápida acidificación, alta temperatura de incubación, excesivo tratamiento térmico, bajo contenido de sólidos, muy baja producción de ácidos y uso de renina (Lucey y Tamehana, 1998).

La leche en polvo descremada, o proteínas concentradas del lactosuero (whey protein concentrate) son ampliamente utilizadas para la estandarización de los sólidos totales del yogurt, esto mejora la textura y reduce la sinéresis (Amatayakul y Sherkat, 2006).

La metodología de superficie-respuesta es una herramienta eficiente en la evaluación de los efectos simultáneos de algunos parámetros tecnológicos y microbiológicos sobre la velocidad de acidificación y el crecimiento de las bacterias iniciadoras durante el proceso de fermentación del yogurt (Kristo y Biladeris, 2003a).

En Colombia la producción industrial del "Suero Costeño" tiene un bajo consumo, porque presenta defectos de calidad tales como: textura granulosa, sinéresis y consistencia variable (Cueto y Garcés, 2007). En este trabajo se evaluaron los efectos simultáneos de las variables de proceso (sólidos totales, temperatura de fermentación, concentración del inoculo) sobre la cinética de acidificación, la viabilidad y la sinéresis del "Suero Costeño".

\section{METODOLOGÍA}

\section{Preparación del "Suero Costeño"}

La leche en polvo se disuelve en agua destilada junto con el lactosuero parcialmente desmineralizado su composición aparece en la tabla 2, después, la mezcla se agitó para disolver bien, luego se calentó a $80^{\circ} \mathrm{C}$ por 20 minutos. Después del tratamiento térmico se inoculo a las temperaturas de fermentación $\left(27.7-39.4^{\circ} \mathrm{C}\right)$ las fermentación se monitoreo por 12 horas con las concentraciones de bacterias lácticas establecidas (0.97-6.00\%), luego de obtenidos los coágulos, se realizó su ruptura y la separación del $20 \%$ del lactosuero en relación al volumen inicial de leche, 
haciendo pasar la mezcla por un filtro. Para conseguir una consistencia adecuada se realizo una homogenización y se adiciono $1.2 \%$ de sal del volumen inicial de leche (Espinal y Barrera, 2000). Se realizaron combinaciones de las cepas Lactococcus lactis Subs. Lactis (ATCC29146) y Lactobacillus Para casei Subs paracasei (ATCC 334), en las proporciones: 3:2 (v/v) para cada nivel.

\section{Estudio de la cinética de acidificación}

Las mediciones del $\mathrm{pH}$ durante la fermentación se realizaron a intervalos de 1 hora hasta 16 horas, la velocidad máxima de acidificación (Vmax) se calculó de acuerdo a la Ecuación 1 (Kristo y Biladeris, 2003b)

$\operatorname{Vmax}=(\mathrm{dpH} / \mathrm{dt})_{\max }$

\section{Medida de la sinéresis}

Después de dos días de almacenamiento refrigerado a $4^{\circ} \mathrm{C}$ se agitó el suero costeño por 2 minutos a $400 \mathrm{rpm}$ con un agitador magnético y posteriormente se centrifugaron a $5000 \mathrm{~g}$ a $20^{\circ} \mathrm{C}$. La sinéresis se calculó como la cantidad de líquido que se separa del gel, debido a la centrifugación con relación a la masa total del gel que fue centrifugada (Aichinger y Servais, 2003).

\section{Viabilidad}

Se utilizo la técnica de recuento estándar en placa en superficie, la cual suministró información sobre el número de células viables en términos de UFC/g del suero costeño

\section{Modelo estadístico}

Se realizaron veinte experimentos de acuerdo a un diseño central compuesto rotable de segundo orden con tres variables y cinco niveles para cada variable. Las variables independientes fueron: nivel de sólidos totales (ST), que depende de la adición del lactosuero en polvo parcialmente desmineralizado, temperatura de fermentación (TF), y concentración del inóculo (CI), que es función del volumen de inóculo por unidad de volumen de leche a fermentar. Los resultados de las variables anteriormente mencionadas se consignan en la tabla 1. La composición del suero parcialmente desmineralizado producido industrialmente se describe en la tabla 2. Los parámetros de los veinte experimentos se muestran en la tabla 3.

Tabla 1: Factores y Niveles

\begin{tabular}{|l|c|c|c|c|c|c|}
\hline Factores & Niveles \\
\hline Sólidos totales $\left(\mathrm{X}_{1}\right)$ & $\mathrm{ST}$ & 10.6 & 12.0 & 14.0 & 16.0 & 17.3 \\
\hline Temperatura de fermentación $\left({ }^{\circ} \mathrm{C}\right)\left(\mathrm{X}_{2}\right)$ & $\mathrm{TF}$ & 27.6 & 30.0 & 33.5 & 37.0 & 39.4 \\
\hline Concentración de inoculo $(\% \mathrm{v} / \mathrm{v})\left(\mathrm{X}_{3}\right)$ & $\mathrm{Cl}$ & 0.97 & 2.0 & 3.5 & 5.0 & 6.0 \\
\hline
\end{tabular}

Tabla 2: Composición del lactosuero en polvo parcialmente desmineralizado

\begin{tabular}{|c|c|c|c|}
\hline Componentes & Porcentaje \% $(\mathrm{p} / \mathrm{p})$ & Componentes & Porcentaje \% $(\mathrm{p} / \mathrm{p})$ \\
\hline Lactosa & 86,78 & Proteína & 2,86 \\
\hline Ceniza & 6,11 & Sal & 1,56 \\
\hline Humedad & 4,20 & Grasa y acidez titulable & 0,10 y 0,08 \\
\hline
\end{tabular}

Se utilizó la metodología de superficie de respuesta para establecer los efectos simultáneos de las variables independientes en el proceso de acidificación, viabilidad y sinéresis del suero costeño. Los ensayos se realizaron por triplicado. El análisis estadístico de los datos se realizo con el programa MINITAB14, mediante pruebas de varianza (ANOVA), manteniendo un intervalo de confianza del $95 \%$ para evaluar el efecto principal de cada factor y el efecto de interacción entre los mismos sobre la respuesta. 
Todos los términos del modelo de superficie respuesta de segundo orden polinomial, fueron llenados para cada respuesta basada en la ecuación 2 , donde $\beta_{0}, \beta_{1} \ldots \beta_{23}$ representan los coeficientes de regresión, con $\beta_{0}$ como intercepto, $\beta_{1}, \beta_{2}$ y $\beta_{3}$ son los efectos lineales, $\beta_{11}, \beta_{22}$ y $\beta_{33}$ son los efectos cuadráticos, $\beta_{12}, \beta_{13}$ y $\beta_{23}$ son las interacciones y $\varepsilon$ es el error aleatorio, $X_{1}, X_{2}$ y $X_{3}$ son las variables independientes (ST, TF y $\mathrm{Cl}$ ) respectivamente. Para simplificar el modelo, solamente se incluyeron los coeficientes que tienen significancia estadística es decir $\mathrm{P} \leq 0.05$.

$Y=\beta_{0}+\beta_{1} X_{1}+\beta_{2} X_{2}+\beta_{3} X_{3}+\beta_{11} X_{1}^{2}+\beta_{22} X_{2}^{2}+\beta_{33} X_{3}^{2}+\beta_{12} X_{1} X_{2}+\beta_{13} X_{1} X_{3}+\beta_{23} X_{2} X_{3}+\varepsilon$

Tabla 3: Diseño Experimental

\begin{tabular}{|c|c|c|c|}
\hline Ensayos & Temperatura & Sólidos Totales & $\begin{array}{l}\text { Concentración } \\
\text { Inóculos }\end{array}$ \\
\hline 1 & 33,5 & 14,0 & 3,5 \\
\hline 2 & 37,0 & 12,0 & 5,0 \\
\hline 3 & 30,0 & 16,0 & 5,0 \\
\hline 4 & 39,38 & 14,0 & 3,5 \\
\hline 5 & 33,5 & 14,0 & 3,5 \\
\hline 6 & 33,5 & 10,63 & 3,5 \\
\hline 7 & 30,0 & 16,0 & 2,0 \\
\hline 8 & 37,0 & 16,0 & 5,0 \\
\hline 9 & 33,5 & 14,0 & 3,5 \\
\hline 10 & 37,0 & 16,0 & 2,0 \\
\hline 11 & 37,0 & 12,0 & 2,0 \\
\hline 12 & 33,5 & 14,0 & 6,02 \\
\hline 13 & 27,6 & 14,0 & 3,5 \\
\hline 14 & 30,0 & 12,0 & 2,0 \\
\hline 15 & 33,5 & 14,0 & 0,97 \\
\hline 16 & 30,0 & 12,0 & 5,0 \\
\hline 17 & 33,5 & 14,0 & 3,5 \\
\hline 18 & 33,5 & 14,0 & 3,5 \\
\hline 19 & 33,5 & 14,0 & 3,5 \\
\hline 20 & 33,5 & 17,36 & 3,5 \\
\hline
\end{tabular}

\section{RESULTADOS Y DISCUSIÓN}

La tabla 4 consigna los resultados obtenidos para cada uno de los factores estudiados, con respecto a Vmax, Sinéresis y Viabilidad (LogN). Por otra parte, las ecuaciones 3 a 5 son obtenidas según el modelo ajustado de la ecuación 2, para así llevar a cabo la realización de las gráficas de Vmax, viabilidad y sinéresis (figuras 1 a 3 , respectivamente).

Las ecuaciones que describen los efectos simultáneos de ST, TF y Cl sobre Vmax, Sinéresis y LogN en suero costeño se presentan a continuación:

$$
\begin{array}{lc}
308.455-22.822 \mathrm{X}_{1}+0.935 \mathrm{X}_{1}^{2} & \text { Vmax } \\
187.47-19.785 \mathrm{X}_{1}-0.2 \mathrm{X}_{1} \mathrm{X}_{2} & \text { Sinéresis } \\
-49.6081+3.553 \mathrm{X}_{2}-0.0520 \mathrm{X}_{2}^{2} & \text { Viabilidad (LogN) }
\end{array}
$$


Tabla 4: Coeficientes de regresión del modelo polinomial de segundo orden para la variable de respuestas $(\mathrm{C}=$ Constante, $\mathrm{TF}=\mathrm{Temperatura}$ de fermentación, $\mathrm{ST}=\mathrm{Só}$ lidos totales; $\mathrm{Cl}=\mathrm{Concentración}$ de inóculo; R2= Coeficiente de correlación. ${ }^{*} \mathrm{P} \leq 0.001 ;{ }^{* *} \mathrm{P} \leq 0.01 ;{ }^{* * *} \mathrm{P} \leq 0.05$ )

\begin{tabular}{|c|c|c|c|}
\hline Factores & Vmax $(\mathrm{pH} / \mathrm{min})$ & Sinéresis $(\%)$ & LogN \\
\hline $\mathbf{C}$ & $308,455^{* * *}$ & $187,47^{* *}$ & $-49,6081^{* * *}$ \\
\hline $\mathbf{T F}$ & $-6,306$ & $-1,450$ & $3,5553^{*}$ \\
\hline $\mathbf{S T}$ & $-22,882^{* * *}$ & $-19,785^{*}$ & $-0,5296$ \\
\hline $\mathbf{C I}$ & $-4,624$ & $-1,346$ & $-0,4526$ \\
\hline $\mathbf{( T F})^{2}$ & 0,119 & 0,068 & $-0,0520^{*}$ \\
\hline $\mathbf{( S T})^{2}$ & $0,935^{* *}$ & $0,826^{*}$ & 0,0166 \\
\hline $\mathbf{( C I})^{2}$ & 0,484 & 0,164 & 0,0728 \\
\hline $\mathbf{T x} \mathbf{S T}$ & $-0,168$ & $-0,200$ & 0,0036 \\
\hline $\mathbf{T} \mathbf{x} \mathbf{C I}$ & 0,176 & 0,038 & $-0,0010$ \\
\hline $\mathbf{S T} \mathbf{x} \mathbf{C l}$ & $-0,358$ & $-0,058$ & $-0,0008$ \\
\hline $\mathbf{R}^{2}$ & 0.985 & 0.989 & 0.987 \\
\hline
\end{tabular}

\section{Cinética de acidificación y viabilidad}

La velocidad máxima de acidificación fue afectada significativamente por el nivel de sólidos totales tanto por los términos lineal y cuadrático (ver ecuación 3). Según la figura 1, la velocidad máxima disminuye con el incremento de la concentración de sólidos totales, mientras que si la temperatura aumenta, la velocidad máxima lo hace muy poco, también los sólidos totales afectan de forma negativa la velocidad máxima de acidificación y los mayores valores de la velocidad máxima se obtienen a bajos niveles de sólidos totales, estos resultados fueron similares a los obtenidos por (Kristo y Biladeris, 2003a). Los efectos de los sólidos totales se deben a la capacidad amortiguadora de las proteínas de la leche y los fosfatos, como se utiliza lactosuero parcialmente desmineralizado, estos constituyentes aumentan, protegiendo a las bacterias de los $\mathrm{pH}$ bajos (Kristo y Biladeris, 2003b).

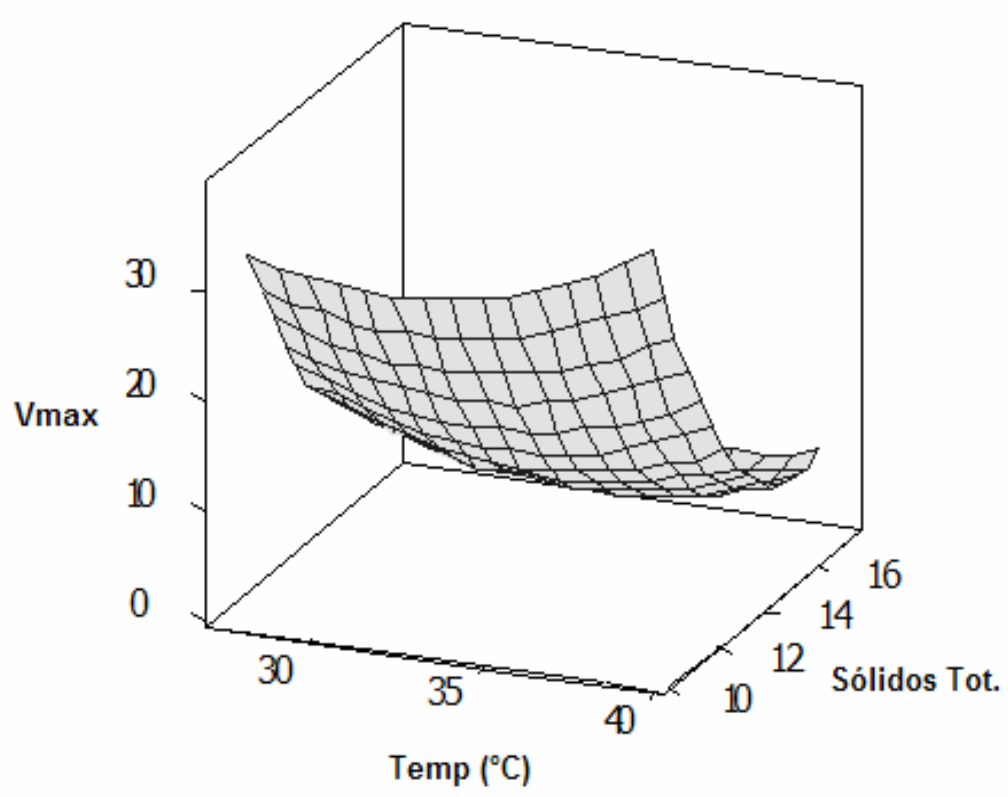

Fig.1: Superficie respuesta para Vmax en función de temperatura y de sólidos totales 
El lactosuero mineralizado inhibe el proceso de fermentación cuando reemplaza parcialmente a la leche descremada en polvo debido, a la alta fuerza iónica, pero cuando se utiliza lactosuero desmineralizado la alta concentración de lactosa ocasiona una elevada producción de acido láctico (Torres et al, 2006).

En el caso de la viabilidad, ésta se incrementa con el aumento en la temperatura hasta los $35^{\circ} \mathrm{C}$, para descender finalmente hasta los $40^{\circ} \mathrm{C}$, mientras que el aumento en los sólidos totales no parece afectar a la viabilidad, puesto que dicho factor aumenta junto con los sólidos totales. Este comportamiento puede apreciarse en la figura 2

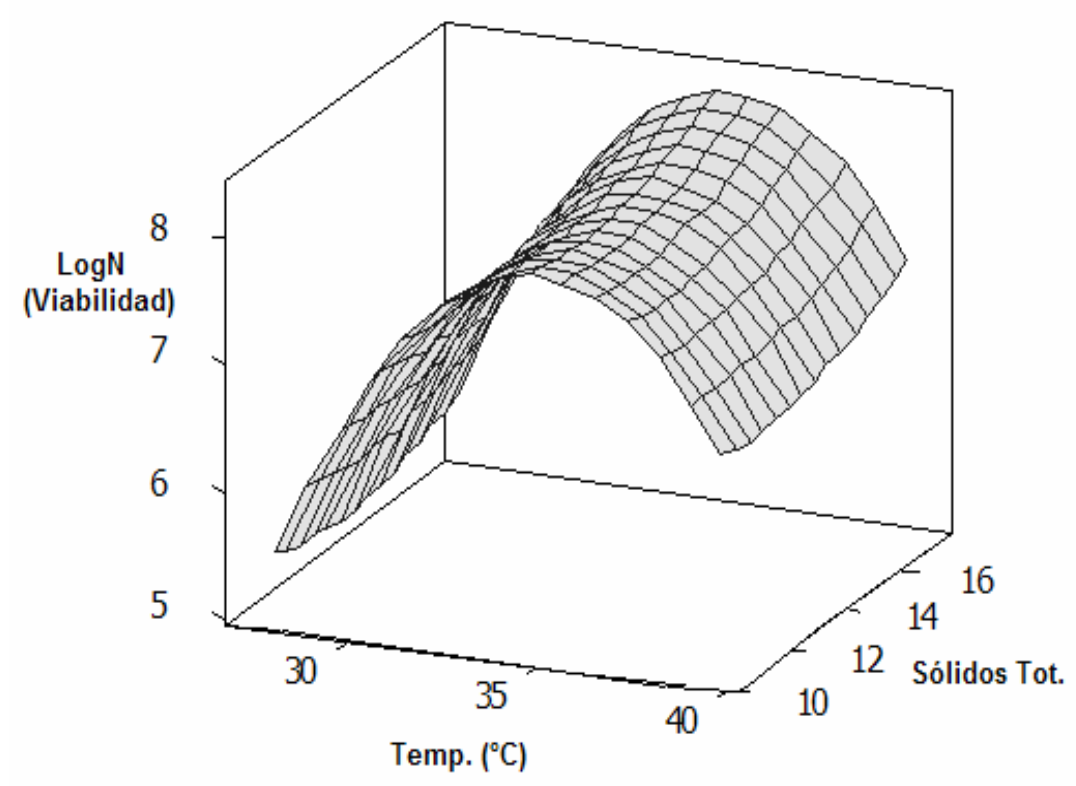

Fig. 2: Superficie respuesta para LogN en función de temperatura y de sólidos totales

Los datos de la ecuación 5 muestran que la viabilidad solamente depende de la temperatura de fermentación tanto del termino lineal como del cuadrático por lo tanto seleccionando la temperatura de fermentación apropiada, se pueden obtener los niveles de cultivos prebióticos exigidos por la normas internacionales en el producto. La temperatura de fermentación afecta fundamentalmente el crecimiento de las bacterias del "Suero costeño" y por lo tanto su estructura y sabor (Castillo y Lucey, 2005). La importancia de la producción de acido se debe a que contribuye a la desestabilización de las micelas de caseínas mediante el paso del fosfato y del calcio de un estado coloidal a una forma soluble lo que causa disminución del calcio de las micelas y su precipitación.

De acuerdo a los resultados de la tabla 4, la figura 2 y la ecuación 5 , se puede concluir que la cantidad de minerales en el lactosuero no afecto significativamente la viabilidad de las BAL en el "Suero Costeño" debido a que se utilizó lactosuero parcialmente desmineralizado.

La temperatura óptima de crecimiento es de $37^{\circ} \mathrm{C}$, los sólidos totales y la cantidad de inóculo no tienen marcada influencia en la viabilidad, esto está de acuerdo con (Saarela y Morgensen, 2000) quienes reportaron que altos incrementos en las BAL se obtienen a temperaturas de $\left(36-38^{\circ} \mathrm{C}\right)$. Un alto numero de bacterias prebióticas al final de la fermentación es importante para mantener un alto nivel durante el almacenamiento refrigerado (Lourens y Viljoen, 2001)

\section{Sinéresis}

La sinéresis del "Suero Costeño" fue afectada significativamente por el nivel de sólidos totales, tanto por el término lineal como por el cuadrático y por la interacción de la temperatura con los sólidos totales (ver ecuación 4). En la figura 3 se muestra la variación de la sinéresis respecto a la temperatura y los sólidos totales, según la figura, la sinéresis aumenta a medida que se incrementa la temperatura y disminuye cuando se incrementan los sólidos totales, aunque al aumentar la 
temperatura de fermentación la sinéresis aumenta levemente, hay que señalar que el incremento de la temperatura aumenta la velocidad de sinéresis, debido a la relajación de los enlaces y a la desnaturalización de las proteínas que forman la red de caseína (Castillo y Lucey, 2005). La capacidad de retención de agua y la sinéresis disminuyen cuando se incrementa el contenido de proteínas en los sólidos totales, además el aumento de las proteínas del lactosuero en la relación lactosuero:caseína disminuye la sinéresis (Remeuf,2003)

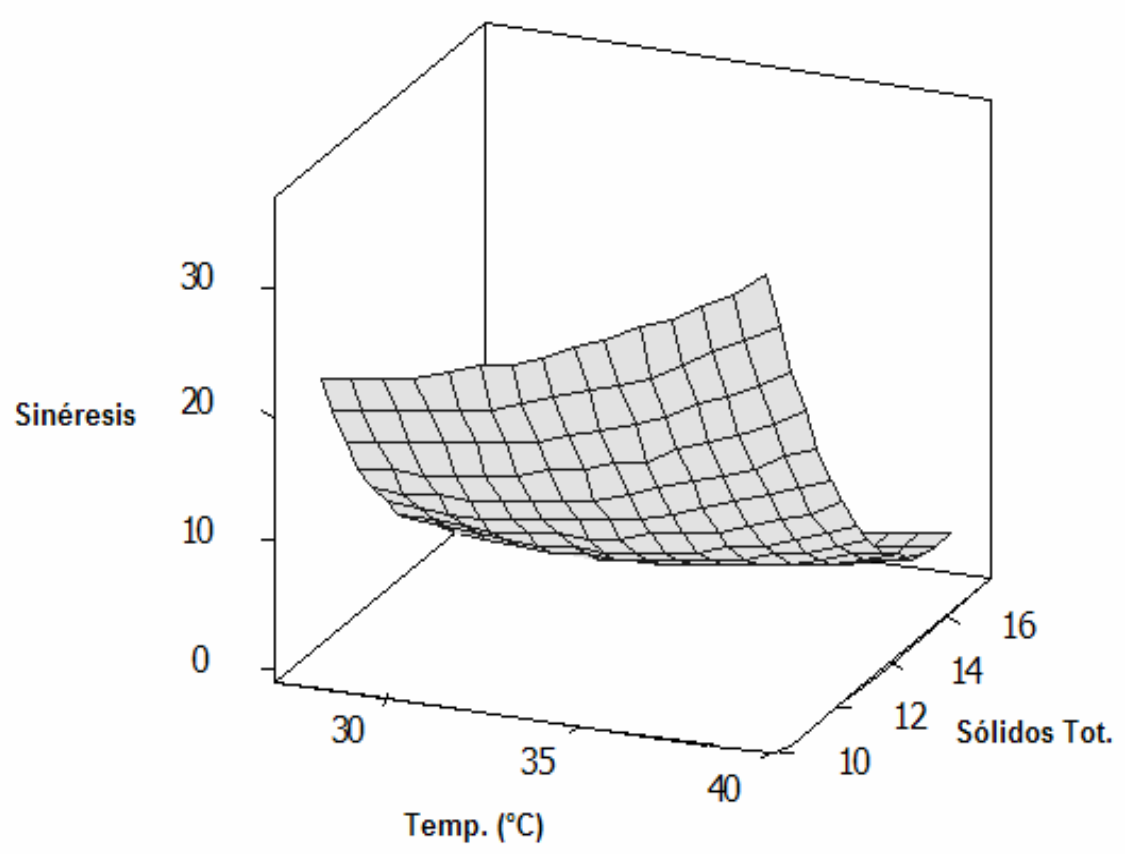

Fig. 3: Superficie respuesta para sinéresis en función de temperatura y de sólidos totales

\section{CONCLUSIONES}

Todos los modelos explican adecuadamente la variación de las respuestas con un alto R2. Los sólidos totales disminuyen la velocidad máxima de acidificación y la sinéresis del "Suero Costeño", mientras la temperatura afecta significativamente la viabilidad de las bacterias acido lácticas.

La variación de la temperatura y la concentración del inóculo pueden causar desnaturalización de las proteínas y aumento de la producción de acido láctico además, con el control de las condiciones estudiadas (Vmax, sinéresis y LogN), se puede lograr obtener un "Suero Costeño" de buena calidad y aceptabilidad, esto es importante para una industria que ha iniciado su producción en Colombia.

\section{REFERENCIAS}

Aichinger, P. y C. Servais; Fermentation of a skim milk concentrate with Streptococcus thermophilus and chymosin: structure, viscoelasticity and syneresis of gels. Colloids and Surface: 31, 243-255 (2003).

Amatayakul, T. y F. Sherkat, F. Physical characteristics of set yoghurt made with altered with altered casein to whey protein ratios and EPS producing starter cultures at 9 and $14 \%$ total solids. Food Hydrocolloids: 20, 314-324 (2006).

Castillo, M. y J. Lucey; Effect of temperature and inoculum concentration on gel microstructure, permeability and syneresis kinetics Cottage cheese-type gels. International Dairy journal: 16, 153-163 (2005).

Chamie, Q. y O. Garcia; Caracterización fisicoquímica del suero costeño. Trabajo de grado, Universidad de la Sabana. Bogotá-Colombia (1999). 
Cueto, C y F. Garcés; Preliminary studies on the microbiological characterization of lactic acid bacteria in Suero costeño, a Colombian traditional fermented milk product. Revista latinoamericana de microbiología: 49, 11-17 (2007).

Espinal, G. y S. Barrera; Inventario y desarrollo de la tecnología de productos lácteos campesinos en Colombia. ICTA (2000).

Farelo, H.; Caracterización microbiológica y de los parámetros fisicoquímicos relacionados con el proceso de fermentación del suero costeño como producto final elaborado en el Difícil Ariguani. Trabajo de grado. Universidad de la Sabana. Bogotá-Colombia (2002).

Kristo, E. y C. Biliaderis; Modelling of the acidification process and rheological properties of milk fermented with a yogurt starter culture using response surface methodology. Food Chemistry: 83, 437-446 (2003a).

Kristo, E. y C. Biliaderis; Modelling of rheological, microbiological and acidification properties of fermented milk product containing a probiotic strain of Lactobacillus paracasei International Dairy Journal: 13, 517-528 (2003b).

Lourens, A y B. Viljoen; Yogurt as probiotic carrier food. International Dairy Journal: 11, 1-17 (2001)

Lucey, J. y M. Tamehana; A comparison of the formation, rheological properties and microestructure of acid skim milk gels made with a bacterial culture or gluconodelta lactone. Food Research international: 31, 147-155 (1998).

Remeuf, F.; Preliminary observations on the effects of milk fortification and heating on microstructure and physical properties of stirred yoghurt. International Dairy Journal: 13, 773-782 (2003).

Saarela, M. y G. Mogensen; Probiotic bacteria: safety, funcional and technological properties. Journal of Biotechnology: 84, 197-215 (2000).

Torres, M. J y otros cuatro autores; Characterization of the natural microflora of artisanal mexican fresco cheese. Food control: 17, 683-690 (2006). 